\title{
Effects of Oil Pulling On Chemo-radiotherapy Induced Oral Mucositis in Head and Neck Cancer Patients
}

Fizza Saher ${ }^{1}$

Mervyn Hosein ${ }^{2}$

Abne Hasan ${ }^{3}$

Jabbar Ahmed Qureshi ${ }^{4}$

Tazein Amber ${ }^{5}$

Nisa Fatima Sunderjee ${ }^{6}$
BDS

FDS RCS (Eng), FDS RCSE(Edin), FFDRCSI(Ire)

M.D.

BDS

MBBS

OBJECTIVE: To compare the effects of coconut oil pulling on chemo-radiotherapy induced oral mucositis in head and neck cancer patients with Magic mouthwash.

METHODOLOGY: This was a double-blind, randomized controlled trial, total of $n=80$ patients of chemo-radiotherapy induced oral mucositis of head and neck cancer were randomized into two arms A and B. A= Oil pulling using pure coconut oil and $\mathrm{B}=$ commercially prepared Magic Mouthwash. Each arm consisted of $n=40$ patients evaluated for a total duration of nine weeks using the WHO scale of oral mucositis and four different pain scores including Verbal pain intensity scale, Numeric pain intensity scale, Visual analog scale and FACES scale. Patients were evaluated at baseline 0, week 3, 6 and 9.Data was analyzed by using SPSS version 20 .

RESULTS: Total of $n=72$ participants completed the study between December 2017 to August 2018; randomly assigned to Group A $(n=36)$ and group B $(n=36)$. Of these $n=48$ were male and $n=24$ female. In both groups there was a reduction in WHO oral mucositis scores over the time of nine weeks; however, the differences were not statistically significant ( $p=0.633$ ). The two treatments did not differ on the main outcome measure i.e. WHO mucositis scale from baseline, or on any other measure of pain, while followed for the nine weeks of trial period. Adverse effects were similar between the two arms and the most frequently reported side effects were radiation induced rash, mouth fatigue and dry mouth.

CONCLUSION: Oil pulling and magic mouthwash was similar in reducing both the severity of oral mucositis and relieving the pain of chemo radiation induced oral mucositis in head and neck cancer patients. Oil pulling with coconut oil can be used as an alternative therapy to magic mouthwash for treating chemoradiation induced oral mucositis.

KEY WORDS: Oral mucositis, oil pulling, magic mouthwash, coconut oil.

HOW TO CITE: Saher F, Hosein M, Hasan A, Qureshi JA J, Amber T, Sunderjee NF. Effects of oil pulling on chemoradiotherapy induced oral mucositis in head and neck cancer patients. J Pak Dent Assoc 2019;28(1):03-12.

DOI: https://doi.org/10.25301/JPDA.281.03

Received: 25 October 2018, Accepted: 17 December 2018

\section{INTRODUCTION}

$\mathrm{G}$ lobally, the sixth most frequently encountered cancers are head and neck cancers (HNC), categorized into cancers of lip and oral cavity, pharynx, larynx, tongue, salivary glands, nasal cavity and paranasal sinus. ${ }^{1}$ It is the ninth most frequent cause of death

1. Lecturer, Department of Oral Biology, Ziauddin College of Dentistry Karachi.

2. Dean, Ziauddin College of Dentistry, Ziauddin University, Karachi.

3. Consultant Radiation Oncologist, Department of Radiation Oncology, Ziauddin Cancer Hospital Karachi.

4. Lecturer, Department of Pharmacology, Ziauddin College of Medicine.

5. Resident, Department of Internal Medicine, Aga Khan University Hospital.

6. Student, Ziauddin College of Medicine.

Corresponding author: "Dr. Fizza Saher” < fizza.saher@zu.edu.pk > worldwide. ${ }^{2}$ Amongst all $\mathrm{HNC}$, the second most prevalent and often diagnosed cancer in Pakistan are of lip and oral cavity. ${ }^{3}$ Its proportion is much higher in males as compared to females with ratio of $2: 1 .{ }^{4}$ Almost over $90 \%$ of all head and cancers are squamous cell carcinomas (HNSCC). ${ }^{5}$ Based on the Grading, the treatment of HNSCC includes Surgery, Radiotherapy and Chemotherapy. Patients with or without surgery and having locally advanced head and neck cancers, the concomitant chemo-radiation is the standard protocol followed worldwide. ${ }^{6}$

Oral mucositis is the most frequently occurring complication of chemo- radiotherapy for cancer treatment. About $40 \%$ of patients who undergo chemo-radiation encounter this as the earliest symptom. ${ }^{7}$ According to a 
study, the frequency of acute mucositis towards the end of the first week of chemo-radiation is about $33.3 \%$ which gradually progresses until the end of the fifth week to 93.3\%. ${ }^{8}$ Patients usually report with oral soreness, severe pain, discomfort, and gastrointestinal distress, independent of the grade or severity of mucositis. During chemo radiotherapy, the mucosa becomes highly prone to injury due to the rapid rate of mitosis in oral tissues and pain is reported to be the most in tolerable symptom. ${ }^{9}$ Mucositis can directly affects the appetite resulting in weight loss, it can cause difficulty in speech and swallowing, severe dehydration and systemic infections which indirectly affect patient's quality of life and financial burdens related to the treatment. Extreme cases of oral mucositis can hinder the deliverance of radiotherapy; hence the effectiveness is compromised with treatment interruptions. ${ }^{10,11}$ These interruptions can compromise patients health and also directly affect the chances of survival. ${ }^{12,13}$

Most common treatment for such symptoms is Magic mouthwash, which is prescribed to patients for relieving the oral symptoms related to cancer therapy. The combination of a topical analgesic, steroid, antifungal, antibacterial and (perhaps) a mucosal coating agent is included in the formulation but there is no standard recipe for this preparation. ${ }^{14}$ Some possible side effects may include a burning or itching in the mouth, nausea, diarrhea and drowsiness is less likely to occur. It may also alter the taste sensation, resulting in loss of appetite. ${ }^{15}$

Oil pulling is a well known ancient herbal procedure that includes prolonged swishing of oil in the oral cavity to improve oral environment. "Oil pulling" is not a new concept and around 3000BC oil pulling had been discussed in Ayurvedic texts. During 1990's in Russia the concept of oil pulling was reinvented by Dr. F. Karach. ${ }^{16}$ It is currently a well renowned Complementary and Alternative Medicine remedy for different illnesses. ${ }^{17}$ Oil pulling is claimed to reduce the chances of dental caries, bleeding gums, halitosis, xerostomia, cracked lips and for improving overall health related to teeth, gums, and jaws. ${ }^{18}$ Oil pulling can be an alternative cleaning method in those patients where brushing is difficult as in mouth ulceration, or in those who have a tendency to gag as in asthmatics and severe cough. ${ }^{19}$ In oil pulling, a teaspoonful of any kind of oil is swished around the mouth early in the morning preferably before having breakfast, for about 15-20 minutes. The oil is 'pulled' and forced around the oral cavity and at the end the viscous oil should become milky white and thinner, if the guidelines to oil pulling have been followed appropriately. It is then expectorated; the mouth is thoroughly washed with warm saline or normal tap water followed by routine tooth brushing. The therapy can be limited to five to ten minutes, if jaw aches. ${ }^{20}$ The procedure is useful in number of systemic diseases like diabetes, bronchitis, thrombosis, asthma and eczema. ${ }^{21}$

The oils which are commonly used are coconut oil, sesame oil, palm oil and sunflower oil. ${ }^{18}$ Coconut oil is commonly and culturally used throughout the sub continent especially in India and Pakistan. Coconut oil has an exceptional role in the diet with added health and nutritional benefits as it acts as an anti-inflammatory, immune modulator ${ }^{22}$, moisturizer and wounds healer. ${ }^{23,24}$ Oil pulling (coconut oil) was used in this study as it is assumed to reduce inflammatory effects and provide additional health benefits to the oral mucosa. The objective of the study was to compare the effects of coconut oil pulling versus "Magic" mouthwash on chemo-radiotherapy induced oral mucositis in head and neck cancer patients.

\section{METHODOLOGY}

This was a multi institutional, double-blinded, randomized controlled trial conducted at the Department of Radiation Oncology at Ziauddin Hospital North Nazimabad and Atomic Energy Medical Center at JPMC between December 2017 and August 2018. This study received approval from the ethical review committee of Ziauddin University (Ref no. 0411117FSOB). Eligible participants were histopathologically proven consecutive head and neck cancer patients aged between 25 to 65 years, who underwent chemo-radiotherapy, with or without primary surgery. Exclusion criteria included patients whose oral examination was not possible due to limited mouth opening, inability to perform the treatment regimen and patients not willing to stop deleterious habits like consumption of Pan and betel nut, smoking or alcohol. All patients were treated with conventional fractionation (5 fractions every week) with a dose between 60-70 Gy. Sample size was calculated by sealed envelope software. Total sample came out to 62 which were increased to 90 patients to reduce the dropout error and patient's lost to follow-up. The significance level was taken at 5\% and power or confidence interval at $90 \%$, standard deviation of 2.65 and non inferiority limit or bound of error was taken at 2 .

\section{PREPARATION AND DISPENSING OF OIL AND MAGIC MOUTHWASH}

Magic mouthwash was prepared by Ziauddin Hospital pharmacy Clifton campus. The constituents of mouthwash include Mucaine (aluminum hydroxide), Vicous Xylocaine and Hydryllin (diphenhydramine). Commercially available pure coconut oil (C.B.C imported from Malaysia) shown in 
Fig la was purchased from the local market, the composition of which is shown in Fig1b. The trial was kept double blinded to eradicate the observer bias. A third person (lab assistant) who was not part of the study was given the task to dispense both the specimens. The oil and mouthwash was dispensed in the dark amber colored bottles of same size and shape having the same amount Fig $1 \mathrm{c}$ and d, packed individually in separate brown colored opaque envelopes. The envelopes were coded according to the group distribution and at the time of dispensing the investigator were kept uninformed from the group labeling i.e. A and B.

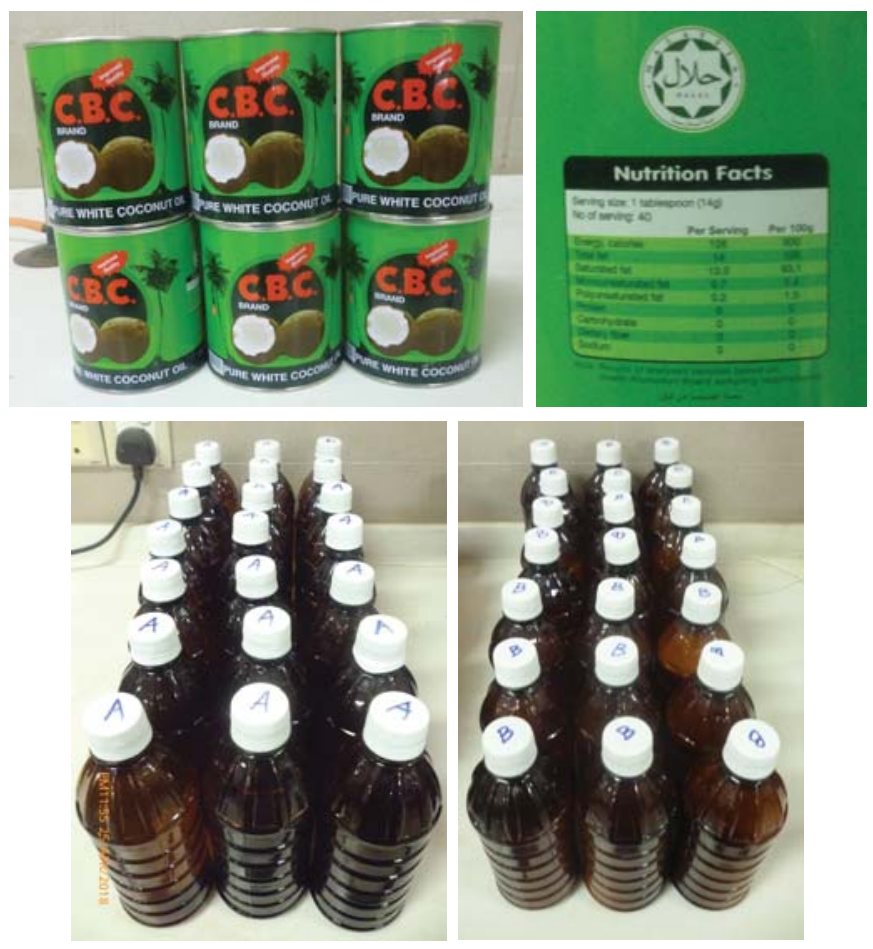

Figure 1: (a) locally available imported pure coconut oil (b) composition of coconut oil (c) (d) Batches of group A and group B bottles.

\section{RANDOMISATION AND TRIAL INTERVENTIONS}

Patients who fulfilled the inclusion criteria and had given the consent for the trial for nine weeks were registered for the study. Before starting the chemo-radiation, enrolled patients were randomized (1:1) to the group A (coconut oil pulling) or standard oral care regimen Group B (magic mouthwash). Randomization was performed by using the sealed envelope randomized sampling technique. ${ }^{25}$ Patients were instructed to swish and then spit out $5 \mathrm{ml}$ (a teaspoon) of either the oil or Magic mouthwash 3 times daily on an empty stomach i.e. morning, afternoon and night for about minimum of 10 minutes for 9 weeks. Patients were advised not to eat and drink anything for about half an hour after swishing and were asked to start the use of oil or magic mouthwash from the day of their first radiation till the end.

\section{EVALUATION AND DATA COLLECTION}

The scoring of chemo-radiation induced oral mucositis was performed by WHO scale of oral mucositis and mucositis induced pain was evaluated using four different pain scores including Verbal pain intensity scale (VPS), Numeric pain intensity scale (NPS), Visual analog scale (VAS) and FACES scale (fig 2), at the following time points: baseline, week 3 during radiotherapy, week 6 and 9 post completion of radiotherapy.

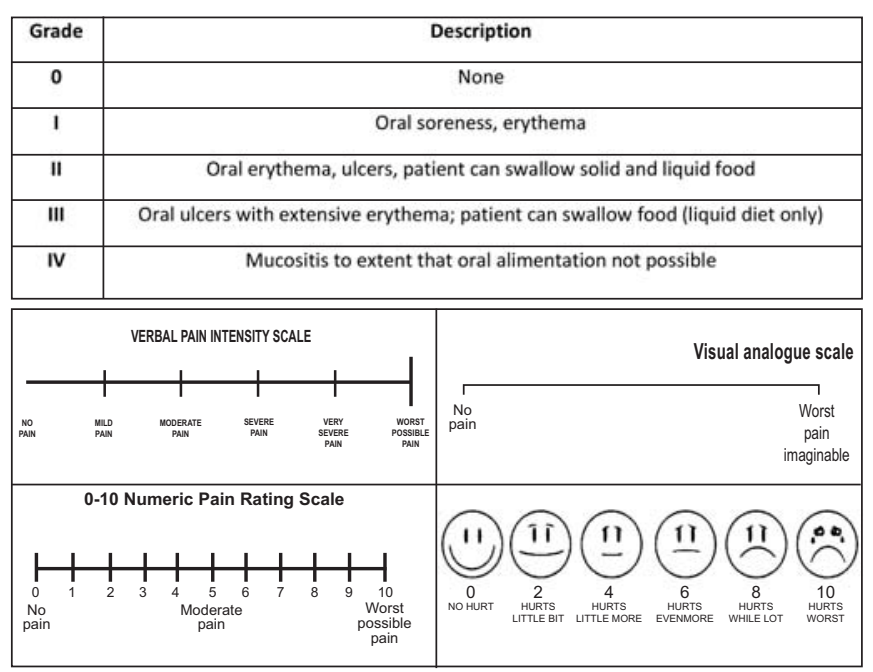

Figure 2: (a) WHO Oral mucositis scale and (b) Pain scales

\section{STATISTICAL ANALYSIS}

Statistical analysis was completed using SPSS version 20. Baseline characteristics were calculated through descriptive statistics. Continuous variables were expressed as means and Standard deviations and categorical variables were expressed as proportions. Association between WHO oral mucositis grades, Verbal Pain intensity scale and FACES scale was performed using Pearson Chi square, while Repeated Measure ANOVA was used to compare the Visual Analogue Scale and Numeric Pain Scale.

\section{RESULTS}

Total $\mathrm{n}=90$ patients were interviewed and screened for the trial out of which $n=6$ patients did not fulfill the inclusion criteria and $n=4$ patients did not give consent. $\mathrm{N}=80$ patients were then allocated to group A (oil pulling) and B (magic mouthwash) containing $n=40$ in each arm. During followup $n=3$ patients were lost in group A due to change in 
radiation center and one due to death. In group $\mathrm{B}, \mathrm{n}=2$ were lost to follow up due to change in radiation center and $n=2$ due to discomfort and lack of compliance. In the end total $n=36$ patients in group $A$ and $n=36$ in group $B$ were evaluated and analyzed for the trial.

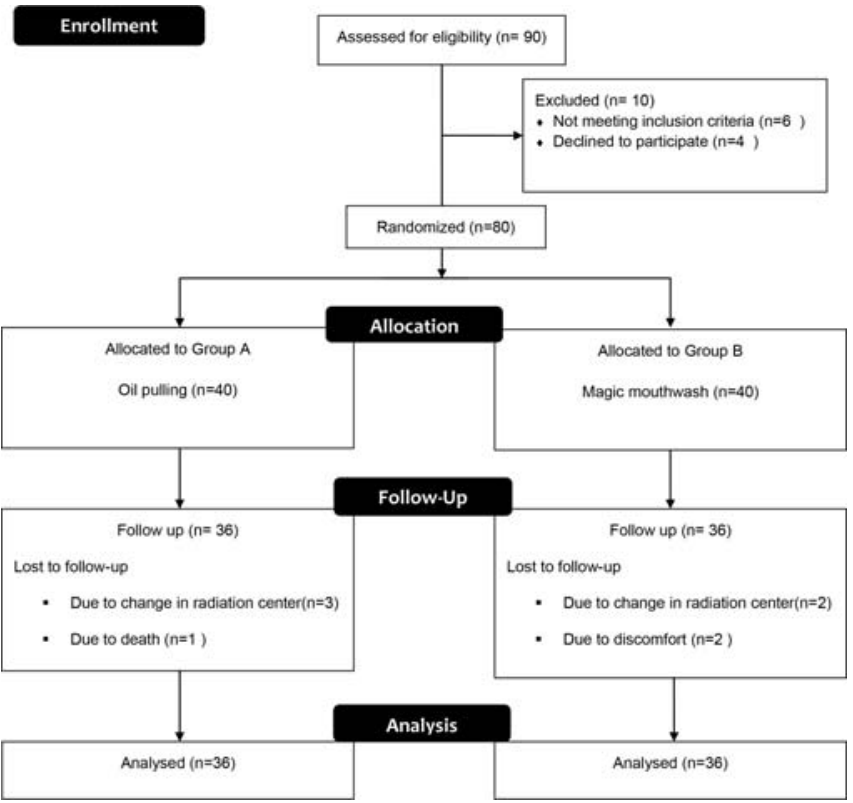

Figure 3: Consort Flow Chart

\section{STUDY POPULATION AND DEMOGRAPHICS}

The study population consisted of $\mathrm{n}=24(33.3 \%)$ women and $\mathrm{n}=48(66.7 \%)$ men, ranging from 25 to 65 years (mean $48.15 \pm 10.79)$. Good patient compliance was observed in both arms.

Baseline characteristics were comparable between the two groups (Table 1). Majority of patients had their tumour in

Table 1: Baseline characteristics

\begin{tabular}{|c|c|c|c|c|c|c|}
\hline & \multicolumn{2}{|c|}{ Coconut oil } & \multicolumn{2}{|c|}{ Magic Mouthwash } & \multicolumn{2}{|c|}{ Total } \\
\hline & $\mathrm{N}$ & $\%$ & $\mathrm{~N}$ & $\%$ & $\mathrm{~N}$ & $\%$ \\
\hline $\begin{array}{l}\text { Age in years } \\
\text { Mean } \\
\text { S.D }\end{array}$ & \multicolumn{2}{|c|}{$\begin{array}{l}48.42 \\
10.41\end{array}$} & \multicolumn{2}{|c|}{$\begin{array}{l}47.89 \\
11.31\end{array}$} & \multicolumn{2}{|c|}{$\begin{array}{l}48,15 \\
10.79\end{array}$} \\
\hline \multicolumn{7}{|l|}{ Gender } \\
\hline Male & 28 & 77.8 & 20 & 55,6 & 48 & 66.7 \\
\hline Female & 8 & 22.2 & 16 & 44.4 & 24 & 33.3 \\
\hline \multicolumn{7}{|l|}{ Education } \\
\hline Nil & 5 & 13.9 & 10 & 27.8 & 15 & 20.8 \\
\hline Primary & 8 & 22.2 & 16 & 44.4 & 24 & 33.3 \\
\hline Secondary & 7 & 19.4 & 3 & 8.3 & 10 & 13.9 \\
\hline Matric & 7 & 19.4 & 4 & 11.1 & 11 & 15.3 \\
\hline Inter & 7 & 19.4 & 1 & 2.8 & 8 & 11.1 \\
\hline Graduate & 2 & 5.6 & 2 & 5.6 & 4 & 5.6 \\
\hline \multicolumn{7}{|l|}{ Ethinicity } \\
\hline Punjabi & 5 & 13.9 & 2 & 5.6 & 7 & 9.7 \\
\hline Sindhi & 6 & 16.7 & 9 & 25 & 15 & 20.8 \\
\hline Balochi & 4 & 11.1 & 5 & 13.9 & 9 & 12.5 \\
\hline Pakhtun & 3 & 8.3 & 4 & 11.1 & 7 & 9.7 \\
\hline Muhajir & 17 & 47.2 & 16 & 44.4 & 33 & 45.8 \\
\hline Other & 1 & 2.8 & 0 & 0 & 1 & 1.4 \\
\hline
\end{tabular}

\begin{tabular}{|c|c|c|c|c|c|c|}
\hline \multicolumn{7}{|l|}{ Deleterious Habits } \\
\hline Smoking & 9 & 25 & 9 & 25 & 18 & 25 \\
\hline Pan/Chalia & 23 & 63.9 & 22 & 61.1 & 45 & 62.5 \\
\hline Naswar & 9 & 25 & 10 & 27.8 & 19 & 26.4 \\
\hline Alcohol & 1 & 2.8 & 2 & 5.6 & 3 & 4.2 \\
\hline Gutka & 16 & 44.4 & 15 & 41.7 & 31 & 43.1 \\
\hline \multicolumn{7}{|l|}{ Site of tumour } \\
\hline Lips & 3 & 8.3 & 12 & 2.8 & 4 & 5.6 \\
\hline Buccal mucosa & 14 & 38.9 & 15 & 41.7 & 29 & 40.3 \\
\hline Alveolar mucosa & 8 & 22.2 & 7 & 19.4 & 15 & 20.8 \\
\hline Tongue & 2 & 5.6 & 4 & 11.1 & 6 & 8.3 \\
\hline Palate & 1 & 2.8 & 2 & 5.6 & 3 & 4.2 \\
\hline Floor of mouth & 1 & 2.8 & 0 & 0 & 1 & 1.4 \\
\hline Larynx & 4 & 11.1 & 3 & 8.3 & 7 & 9.7 \\
\hline Nasopharynx & 2 & 5.6 & 1 & 2.8 & 3 & 4.2 \\
\hline Oropharynx & 1 & 2.8 & 2 & 5.6 & 3 & 4.2 \\
\hline Salivary glands & 0 & 0 & 1 & 2.8 & 1 & 1.4 \\
\hline \multicolumn{7}{|l|}{ Tumour size } \\
\hline $\mathrm{Tl}$ & 4 & 11.1 & 3 & 8.3 & 7 & 9.7 \\
\hline $\mathrm{T} 2$ & 19 & 52.8 & 20 & 55.6 & 39 & 54.2 \\
\hline T3 & 9 & 25 & 9 & 25 & 18 & 25 \\
\hline $\mathrm{T} 4$ & 4 & 11.1 & 4 & 11.1 & 8 & 11.1 \\
\hline \multicolumn{7}{|l|}{ Nodal involvement } \\
\hline N0 & 16 & 44.5 & 12 & 33.3 & 28 & 38.9 \\
\hline $\mathrm{NI}$ & 13 & 36.1 & 16 & 44.5 & 29 & 40.3 \\
\hline N2 & 7 & 19.4 & 8 & 22.2 & 15 & 20.8 \\
\hline \multicolumn{7}{|l|}{ Metastasis } \\
\hline Mo & 33 & 91.7 & 35 & 97.2 & 68 & 94.4 \\
\hline MI & 3 & 8.3 & 1 & 2.8 & 4 & 5.6 \\
\hline \multicolumn{7}{|l|}{ Stage } \\
\hline 1 & 14 & 38.9 & 9 & 25 & 23 & 31.9 \\
\hline 2 & 7 & 19.4 & 12 & 33.4 & 19 & 26.4 \\
\hline 3 & 7 & 19.4 & 10 & 27.8 & 17 & 23.6 \\
\hline 4 & 8 & 22.2 & 5 & 13.9 & 13 & 18.1 \\
\hline \multicolumn{7}{|l|}{ Surgery } \\
\hline With & 28 & 77.8 & 31 & 56.1 & 59 & 81.9 \\
\hline Without & 8 & 11.1 & 5 & 13.9 & 13 & 18.1 \\
\hline \multicolumn{7}{|l|}{ Histopathology } \\
\hline $\begin{array}{c}\text { Squamous cell } \\
\text { carcinoma }\end{array}$ & 36 & 100 & 35 & 97.2 & 71 & 98.6 \\
\hline $\begin{array}{l}\text { Mucoepidermoid } \\
\text { carcinoma }\end{array}$ & 0 & 0 & 1 & 2.8 & 1 & 1.4 \\
\hline
\end{tabular}

the buccal mucosa $(40.3 \%)$ and most were Stage I tumors (31.9\%). The reported deleterious habits showed Pan and Chalia (62.5\%) as the most common habit. Almost all the patients had SCC (98.6) and only one had mucoepidermoid carcinoma (1.4\%).Chemo-radiation were given to all of the study patients $(100 \%)$.

\section{WHO ORAL MUCOSITIS SCALE}

Of the 72 patients all reported grade $0(100 \%)$ at baseline in both the treatment groups (Figure. 4). At week 3 around 18 patients $(50 \%)$ progressed to clinically significant grade 3 mucositis in each arm but association between grades of oral mucositis and intervention was statistically insignificant ( $p$ value 0.834 ). Overall reduction was seen at week 6 and the mucositis grade was found to be clinically significant as it reduces to grade $2(34.6 \%)$ in group A and to grade 1 $(43.9 \%)$ in group B, whereas association between grades of oral mucositis and intervention was statistically insignificant at week 6 (p value 0.144$)$. At the final follow-up week i.e. week 9 , the mucositis had almost dropped to grade 0 in $52.4 \%$ of patients in group A and to $47.6 \%$ in group B. Association between grades of oral mucositis and intervention was statistically insignificant at week 9 ( $p$ value 0.633 ) ( Figure 5) 
Figure 4: Frequency of grades of WHO mucositis scale on 3 weekly follow up
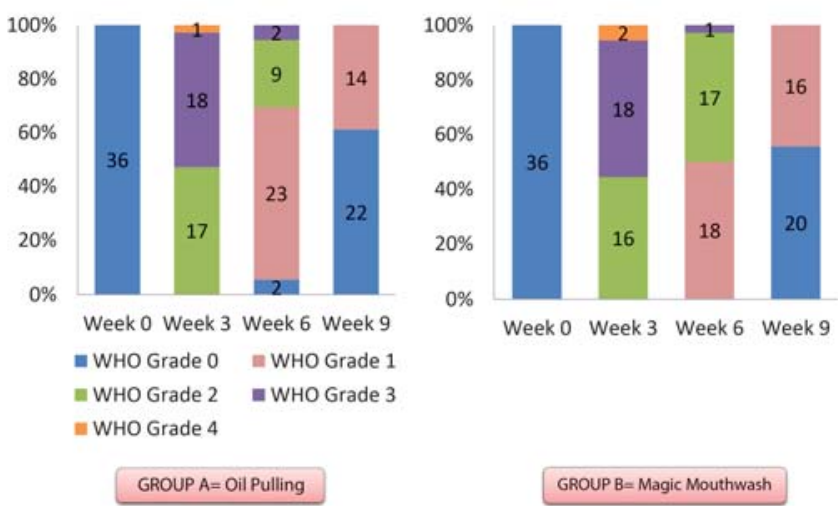

Figure 5: Comparison of Mean WHO mucositis scale

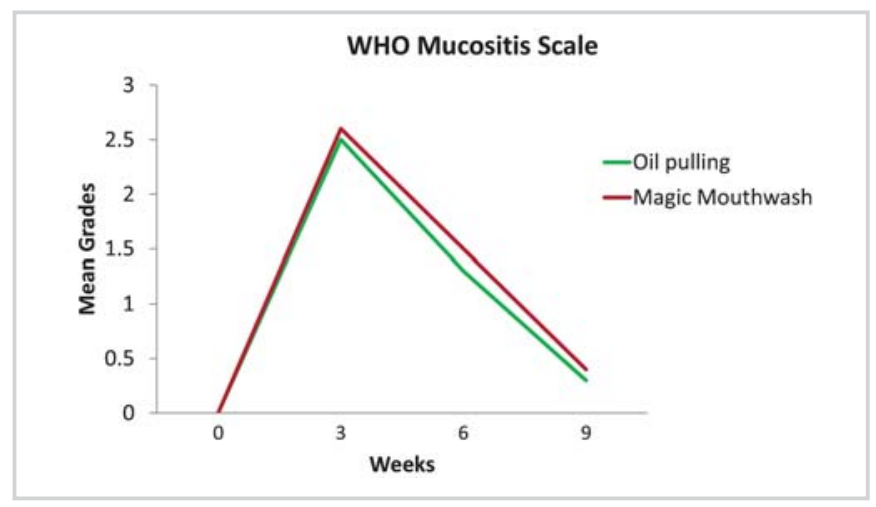

\section{VISUAL ANALOG SCALE}

At week 0 there was no sign of pain in both the groups whereas the scores increased at week 3(Figure 6a). Out of 36 patients, 11 recorded a score of $20 \mathrm{~mm}(30.6 \%)$ in group $\mathrm{B}$ and highest score recorded was $60 \mathrm{~mm}$ in $8(22.2 \%)$ patients. In group $\mathrm{A}$ the highest score recorded was also $60 \mathrm{~mm}$ but in 10 patients $(27.8 \%)$ and the least score was $10 \mathrm{~mm}$ recorded in only $1(2.8 \%)$ patient. A repeated measures ANOVA with a Sphericity correction determined that mean VAS differed statistically significant between time points $(F=286$, $\mathrm{P}<0.0001)$. Post hoc tests using the LSD correction revealed that time elicited an increase in VAS from Week 0 to 3 -weeks after induction in both groups $(.00+/-.00$ versus $38.2+/-16, \mathrm{P}<0.0001)$. However, there was a reduction in VAS from Week 3 to week 6(38.2+/-16 versus $20.1+/-12$, $\mathrm{P}<0.0001)$. Further reduction was observed in VAS from Week 6 to week $9(20.1+/-12$ versus $5.5+/-8.5$, $\mathrm{P}<0.0001)$.There was no statistically significant difference in time* induction group interaction $(\mathrm{F}=.155, \mathrm{P}<.926)$. Neither there was no difference between the two induction groups on VAS after chemo radiation $(\mathrm{F}=.012, \mathrm{P}<.911)$.

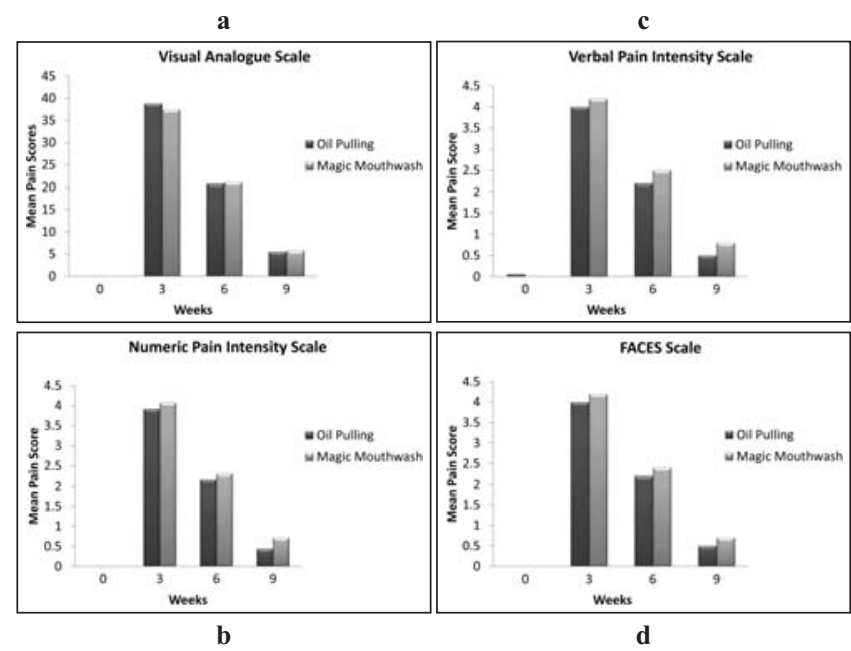

Figure 6: (a). Visual Analogue Scale (b). Numeric Pain Intensity scale (c). Verbal Pain intensity scale

(d). FACES scale ( $\mathrm{A}=$ oil pulling, $\mathrm{B}=$ Magic mouthwash)

\section{NUMERIC PAIN INTENSITY SCALE}

At week 0 both the groups were free of pain (100\%). At week 3 the highest reading in group A was recorded as 6 in $9(25 \%)$ patients while group B showed 8 as the highest recorded numeric point in $2(5.6 \%)$ patients(Fig 6b). A repeated measures ANOVA with a Sphericity correction determined that mean Numeric pain intensity scale differed statistically significant between time points $(\mathrm{F}=318$, $\mathrm{P}<0.0001$ ). Post hoc tests using the LSD correction revealed that time elicited an increase in Numeric pain intensity scale from Week0 to 3-weeks after induction in both groups $(00+/-00$ versus $4+/-1.58, \mathrm{P}<0.0001)$. At week 6 around 21 patients $(58.3 \%)$ reported at scale 2 in group A with 20 $(55.6 \%)$ patients in group B. However, there was a reduction in mean numeric pain intensity from Week 3 to week $6(4+/-$ 1.58 versus $2.24+/-1.1, \mathrm{P}<0.0001)$. Further reduction was observed from Week 6 to week $9(2.24+/-1.1$ versus $.58+/-.9$, $\mathrm{P}<0.0001)$ as 27 patients $(75 \%)$ were free of pain in group A and 21(58.3\%) patients in group B. However there was no statistically significant difference in time* induction group interaction $(\mathrm{F}=.320, \mathrm{P}<.811)$. Neither was there a difference between the two induction groups on Numeric pain intensity scale after chemo-radiation $(\mathrm{F}=.669, \mathrm{P}<.416)$.

\section{VERBAL PAIN INTENSITY SCALE}

Out of 36 patients in group A only one patient suffered from mild pain (2.8\%) at week (Fig 6c).Using Verbal pain intensity scale association between pain and intervention was statistically insignificant at 0 weeks (P value .314). At week $3,18(50 \%)$ patients suffered from moderate pain in 
group A whereas only 14 patients (38\%) had reported moderate pain in group B.

Using Verbal pain intensity scale association between pain and intervention was statistically insignificant at 3 weeks (P value .775). On the follow-up at week 6 both the groups showed similar data and almost $26(72.2 \%)$ patients reported of mild pain. Using Verbal pain intensity scale association between pain and intervention was statistically insignificant at 6 weeks (P value 0.171). Week 9 showed that $21(58.3 \%)$ patients were free of pain while 15 had mild pain (41.7\%) in group B. Group A showed 26(72.2\%) patients had no pain out of 36 patients. Using Verbal pain intensity scale association between pain and intervention was statistically insignificant at 9 weeks ( $P$ value 0.216 ).

\section{FACES SCALE}

All patients in both the groups reported no pain at week 0 (Fig 6d). Around 16(44.4\%) patients in group A and $18(50 \%)$ patients in group B reported at." hurts little more". Using Faces scale association between pain and intervention at week 3 was insignificant ( $\mathrm{p}$ value 0.374 ). At week 6, $24(66.7 \%)$ patients in group A while 26(72.2\%) patients in group B reported at scale "hurts little bit". Using Faces scale association between pain and intervention at week 6was insignificant ( $p$ value 0.379 ). At week $9,23(63.9 \%$ ) patients in group B while 27(75\%) patients were free of pain. Using Faces scale association between pain and intervention at week 9 was insignificant ( $p$ value 0.306 ).

\section{ADVERSE EFFECTS}

At the end of the study the most frequently encountered adverse effect were radiation rash, mouth fatigue and dry mouth (Table 2). However in Group A, $n=34(94.4 \%$ ) patients and in group $\mathrm{B}, \mathrm{n}=36(100 \%)$ patients suffered from radiation induced rash. Nausea and vomiting was the least occurring

\begin{tabular}{|c|c|c|c|c|c|}
\hline \multicolumn{2}{|c|}{ Adverse effects } & \multicolumn{2}{|c|}{ Oil Pulling } & \multicolumn{2}{c|}{ Magic Mouthwash } \\
\cline { 3 - 6 } \multicolumn{2}{|c|}{} & Frequency & \% & Frequency & $\%$ \\
\hline \multirow{2}{*}{ Nausea } & Yes & 1 & 2.8 & 2 & 5.6 \\
\cline { 2 - 6 } & No & 35 & 97.5 & 34 & 94.4 \\
\hline \multirow{2}{*}{ Vomiting } & Yes & 1 & 2.8 & 1 & 2.8 \\
\cline { 2 - 6 } & No & 35 & 97.5 & 35 & 97.2 \\
\hline \multirow{2}{*}{ Diarrhea } & Yes & 4 & 11.1 & 11 & 30.6 \\
\cline { 2 - 6 } & No & 32 & 88.9 & 25 & 69.4 \\
\hline Constipation & Yes & 3 & 8.3 & 2 & 5.6 \\
\cline { 2 - 6 } & No & 33 & 91.7 & 34 & 94.4 \\
\hline Radiation & Yes & 34 & 94.4 & 36 & 100 \\
\cline { 2 - 6 } Rash & No & 2 & 5.6 & 0 & 0 \\
\hline Mouth & Yes & 27 & 75 & 23 & 63.9 \\
\cline { 2 - 6 } Fatigue & No & 9 & 25 & 13 & 36.1 \\
\hline \multirow{2}{*}{ Dry mouth } & Yes & 5 & 13.9 & 11 & 30.6 \\
\cline { 2 - 6 } & No & 31 & 86.1 & 25 & 69.4 \\
\hline
\end{tabular}

Table 2: Frequency of Adverse effects encountered in group A and group B adverse effects in both the arms (Group A=1, Group B=2). Mouth fatigue was the second most common adverse effect reported in both the groups. Group A had $\mathrm{n}=27(75 \%)$ patients whereas group B had $n=23(63.9 \%)$ no. of patients who experienced mouth fatigue followed by dry mouth that occurred in $n=11(30.6 \%)$ in group $B$ and $n=5(13.9 \%)$ patients in group A.

\section{DISCUSSION}

To the best of our knowledge, till today no trial has been done on the efficacy of oil pulling on chemo-radiation induced oral mucositis. This trial compared the effects of coconut oil pulling with the conventional treatment (magic mouthwash) given to the chemo-radiation induced oral mucositis patients. We found that there is no statistically significant difference between the two treatment modalities in reducing the severity of the oral mucositis with its associated pain. The two interventions did not differ on the primary outcome measure i.e. WHO mucositis scale from day 0 , or on any other scales of pain, when followed across the nine weeks of trial period.

As there is no available data of using oil pulling in chemo radiation induced oral mucositis, we are unable to compare the effects of oil pulling with other studies. Up to now, only palifermin, (a recombinant keratinocyte growth factor), has shown significant decrease in the severity and duration of radiation-induced mucositis in HNC. ${ }^{6,26}$ Other treatments, including artificial saliva, antimicrobial agent and analgesics, do not sufficiently control the condition. ${ }^{27}$ No researcher has ever used coconut oil for the reduction of oral mucositis but our results are in agreement with the study done by Suresh Rao et al in 2014 in which they found that gargling with turmeric by head and neck cancer patients undergoing radiation therapy provided significant benefit by delaying and reducing the severity of mucositis. ${ }^{28}$ Triclosan mouthwash was also effective than sodium bi carbonate mouthwash in minimizing chemo-radiation induced oral mucositis with early reversal of symptoms towards the end of chemoradiation. ${ }^{29}$

Currently, there are only a couple of effective medicines present available for the treatment of chemo-radiation induced oral mucositis but the most broadly endorsed topical treatment is a pharmacist prepared liquid mouthrinse commonly known as "magic mouthwash". ${ }^{30,31}$ McGuire et al, proved that the pain relief from these mouthwashes is temporary and they could not be used for the prevention or treatment of mucositis. ${ }^{32}$ According to Kuk et al, mouthwash containing diphenhydramine plus sucralfate, nystatin and dexamethasone was when compared with benzydamine, showed no significant decrease in oral mucositis. ${ }^{33,34}$ Sarvizadeh et al, showed that morphine was more effective in limiting the progression of 
oral mucositis in chemo-radiation patients when compared with the magic mouthwash containing magnesium aluminum hydroxide, viscous lidocaine, and diphenhydramine (also used in our trial). ${ }^{35}$

In our study we used pure coconut oil for alleviating oral mucositis and its related pain, because of its anti inflammatory effects. According to an animal study done by S. Intahphuak et al. virgin coconut oil was useful in the reduction of ear and paw edema. The results showed significant anti inflammatory and anti-nociceptive effects, when virgin coconut oil (VCO) was given in high doses. VCO also inhibits inflammatory markers like prostaglandins, bradykinin, and histamine responsible for pain and edema formation. ${ }^{36}$ In a clinical trial, Daddy et al found that virgin coconut oil was equally effective as triamcinolone for the management of minor recurrent aphthous ulcers (stomatitis). ${ }^{37}$ This study supports our results because both the stomatitis and mucositis have a similar mechanism and expression in terms of inflammation. So using coconut oil in mucositis patients also has the same effects. There are some clinical studies which have proven the anti-gingivitis effects of coconut oil pulling. Recently in 2018, Kaliamoorthy et al. proved that coconut oil pulling is effective than sesame oil pulling for the reduction in severity of gingivitis. ${ }^{38}$ Chalke et al in 2017 reported the use of coconut oil pulling as an adjunctive therapy for plaque-induced gingivitis. ${ }^{39}$ Another study by Peedikayil was done in 2015 reported that coconut oil pulling could be used as an efficient supportive therapy in plaque induced gingivitis. ${ }^{40}$ As we understand, these clinical trials have proven that coconut oil pulling is efficient in an inflammatory disease like gingivitis due to its anti inflammatory effects and possibly supporting its use as a treatment for the reduction of oral mucositis, being the fact that this is also an inflammatory process.

The main reason for the reduction in pain scores in our study could be due to the oil used for oil pulling that is coconut oil. Pain scores were reduced from baseline to the end of week 9 and suggest that there is no statistically significant difference in both the arms. This makes coconut oil equally as effective as magic mouthwash in chemoradiation induced oral mucositis. This phenomenon could be supported by an animal model which showed that VCO decreased the release of inflammatory mediators like COX2 , TNF- $\alpha$ and IL- 6 and the concentration of thiobarbituric acid reactive substance with an increase in antioxidant enzymes. ${ }^{41}$ The second reason could be due to the presence of polyphenols in coconut oil ${ }^{42}$ which possess various biological properties, including anti-nociceptive activities. The proliferative phase of chronic inflammation is suppressed by the anti-nociceptive effect of virgin coconut oil and throughout the process of inflammation; phagocytic cells release lysosomal enzymes which damage the surrounding cells. Gene expression, activation of pro-inflammatory transcription factors and signal transduction is also affected. ${ }^{43}$ Presently, no such treatment exists that can completely resolve or prophylactically treat oral mucositis and is also devoid of any side effects. The major advantage behind the use of coconut oil for oil pulling therapy is due to its safety profile. In an animal toxicity study, an oral dose of $5000 \mathrm{mg} / \mathrm{kg}$ coconut oil was found to be safe and well tolerated. ${ }^{44}$ So, if the patient accidentally swallows the oil, which is an exception, it would not adversely affect the health

In the healing phase the use of coconut oil can be helpful in terms of increased wound healing properties. According to Ibrahim et al, an animal study confirmed a high angiogenic and wound healing property of fermented VCO in both in vitro and in vivo assays that might be mediated by the regulation of Vascular Endothelial Growth Factor signaling pathway. ${ }^{45}$ Horas et al in 2017 showed that topical application of VCO accelerated palatoplasty wound healing showing an increased number of fibroblast cells appearing in the wound, in addition to fewer pain complaints. ${ }^{46}$ This could be a factor which has also worked in our study population increasing the healing capacity in the coconut oil pulling group. Furthermore, in our study, except for mouth fatigue, all cases in the oil pulling group had fewer adverse effects when compared with the magic mouthwash. Fewer patients suffered from dehydration in the oil pulling group when compared with the magic mouthwash. This can be supported through a study done by Agero and Verallo-Rowell, in which they reported that coconut oil, is as effective and safe as mineral oil and can be used as a moisturizer for the treatment of xerosis. VCO showed effectivity through an increase in skin surface lipid levels and significantly enhanced skin hydration..$^{47}$ Due to this phenomenon, usage of coconut oil could be beneficial on a long term basis, even after the completion of chemo-radiation, where patients suffer from complete or partial xerostomia.

\section{CONCLUSION}

Oil pulling and magic mouthwash were similar in reducing both the severity of oral mucositis and relieving the pain of chemo radiation induced oral mucositis in head and neck cancer patients. Oil pulling with coconut oil can be used as an alternative therapy to magic mouthwash for treating chemo-radiation induced oral mucositis.

\section{ACKNOWLEDGEMENTS}

We acknowledge the support of the Ziauddin University. We would like to express our gratitude to Radiation Oncology 
department of Ziauddin hospital and Atomic Energy Medical Center at JPMC for the recruitment of patients. We also thank the clinical staff and health care assistants who have given their support and assistance for this trial. We would also like to thank the patients, who had voluntarily enrolled for the study and given their true support for the betterment of future patients.

\section{CONFLICT OF INTEREST}

None

\section{FUNDING STATEMENT}

This study was fully sponsored by the Ziauddin University.

\section{REFRENCES}

1. Bhurgri Y, Bhurgri A, Usman A, Pervez S, Kayani N, Bashir I, et al. Epidemiological review of head and neck cancers in Karachi. Asian Pacific J cancer prevent: 2006;7:195-200.

2. Organization WH. World Cancer Report 20142014.

3. Sarwar MR, Saqib A. Cancer prevalence, incidence and mortality rates in Pakistan in 2012. Cogent Medicine. 2017;4:1288773. https://doi.org/10.1080/2331205X.2017.1288773

4. Akram S, Mirza T, Aamir Mirza M, Qureshi M. Emerging Patterns in Clinico-pathological spectrum of Oral Cancers. Pak J Medi Sci. 2013;29:783-7.

5. Tariq A, Mehmood Y, Jamshaid M, Yousaf H. Head and neck cancers: Incidence, Epidemiological Risk, and Treatment Options2015. 21-34 p.

6. Le QT, Kim HE, Schneider CJ, Murakozy G, Skladowski K, Reinisch $\mathrm{S}$, et al. Palifermin reduces severe mucositis in definitive chemoradiotherapy of locally advanced head and neck cancer: a randomized, placebo-controlled study. J clini oncology: 2011;29:280814.

https://doi.org/10.1200/JCO.2010.32.4095

7. Ho JKH, Choi WS. Prevention and treatment of oral mucositis caused by chemo- and radiotherapy in head and neck cancer patient. Int J Oral and Maxillofac Surg. 2017;46:144.

https://doi.org/10.1016/j.ijom.2017.02.497

8. Majdaeen M, Kazemian A, Babaei M, Haddad P, Hashemi F. Concomitant boost chemoradiotherapy in locally advanced head and neck cancer: Treatment tolerance and acute side effects. J Cancer Res Therapeuti. 2015;11:24-8.

https://doi.org/10.4103/0973-1482.155098

9. Sroussi Herve Y, Epstein Joel B, Bensadoun RJ, Saunders Deborah P, Lalla Rajesh V, Migliorati Cesar A, et al. Common oral complications of head and neck cancer radiation therapy: mucositis, infections, saliva change, fibrosis, sensory dysfunctions, dental caries, periodontal disease, and osteoradionecrosis. Cancer Medi. 2017;6:2918-31. https://doi.org/10.1002/cam4.1221

10. Murphy BA, Gilbert J, Cmelak A, Ridner SH. Symptom control issues and supportive care of patients with head and neck cancers. Clin Adv Hematol Oncol. 2007;5:807-22.

11. Marcelo Bonomi, Nadia Camille, Krzysztof Misiukiewicz, Asma Latif, Vishal Gupta, Eric Genden, Seth Blacksburg \& Marshall Posner. Assessment and management of mucositis in head and neck cancer patients. Clini Investi. 2012;2:1231-40.

https://doi.org/10.4155/cli.12.120

12. Serap B Yucel ZG, Bilgehan Sahin and Huseyin Kadioglu. Oral Mucositis: A Crucial Problem during Radiation Therapy. J Trauma \& Treat. 2015;4:226.

13. Owlia Fatemeh K, Seid kazem, Gholami Neda. Prevention and Management of Mucositis in Patients with Cancer: a Review Article. Iranian J Cancer Prevent. 2012;5:216-20.

14. Hovan DA. "Magic" mouthwash explained. Fami Pract Oncol Network J. 2014:3

15. Saunders DP, Epstein JB, Elad S, Allemano J, Bossi P, van de Wetering MD, et al. Systematic review of antimicrobials, mucosal coating agents, anesthetics, and analgesics for the management of oral mucositis in cancer patients. Supportive Care in Cancer. 2013;21:3191207.

https://doi.org/10.1007/s00520-013-1871-y

16. Hebbar A, Keluskar V, Shetti da. Oil pulling-Unraveling the path to mystic cure 2010 .

17. Singh A, Purohit B. Tooth brushing, oil pulling and tissue regeneration: A review of holistic approaches to oral health. J Ayurveda Integr Med. 2011;2:64-8.

https://doi.org/10.4103/0975-9476.82525

18. Poonam Tomar SH, Manish Jain, Kuldeep Rana, Vrinda Saxena. Oil Pulling and Oral Health: A Review. IJSS Case Reports \& Reviews 2014;1(3):33-7.

19. Gunjan Garg, Gopesh Manga, Chundawat NS. Ayurvedic Approach In Oral Health \& Hygiene: A Review Int J Ayurveda Pharma Res. $2016 ; 4$

20. Shanbhag VK. Oil pulling for maintaining oral hygiene - A review. J Tradit Complement Med. 2017;7:106-09. https://doi.org/10.1016/j.jtcme.2016.05.004

21. Mustafa Naseem, Muhammad Faheem Khiyani, Hiba Nauman, Muhammad Sohail Zafar, Altaf H Shah, Khalil HS. Oil pulling and importance of traditional medicine in oral health maintenance. Int $\mathrm{J}$ Health Sci. 2017;11.

22. Illam SP NA, Raghavamenon AC. Polyphenols of virgin coconut oil prevent pro-oxidant mediated cell death. Toxicol Mech Methods. 
2017;27:442-50.

https://doi.org/10.1080/15376516.2017.1320458

23. Khan MS, Lari QH, Khan MA. Physico-Chemical and Pharmacological Prospective of Roghan-e-Narjeel (Coconut Oil). Int J Pharma Sci Res. 2015;6:1268-73.

24. Shanbhag VKL. Oil pulling for maintaining oral hygiene - A review. J Traditi Complement Medi. 2017;7:106-09.

https://doi.org/10.1016/j.jtcme.2016.05.004

25. Torgerson DJ, Roberts C. Randomisation methods: concealment. BMJ : British Medical Journal. 1999;319(7206):375-6.

https://doi.org/10.1136/bmj.319.7206.375

26. Henke M, Alfonsi M, Foa P, Giralt J, Bardet E, Cerezo L, et al. Palifermin decreases severe oral mucositis of patients undergoing postoperative radiochemotherapy for head and neck cancer: a randomized, placebo-controlled trial. Journal of clinical oncology: official J Ameri Soci of Clini Oncol. 2011;29:2815-20. https://doi.org/10.1200/JCO.2010.32.4103

27. Rodriguez-Caballero A, Torres-Lagares D, Robles-Garcia M, Pachon-Ibanez J, Gonzalez-Padilla D, Gutierrez-Perez JL. Cancer treatment-induced oral mucositis: a critical review. Int J Oral Maxillofac Surg. 2012;41:225-38.

https://doi.org/10.1016/j.ijom.2011.10.011

28. Rao S, Dinkar C, Vaishnav LK, Rao P, Rai MP, Fayad R, et al. The Indian Spice Turmeric Delays and Mitigates Radiation-Induced Oral Mucositis in Patients Undergoing Treatment for Head and Neck Cancer: An Investigational Study. Integrat cancer therapies. 2014;13:201-10.

https://doi.org/10.1177/1534735413503549

29. Satheeshkumar PS, Chamba MS, Balan A, Sreelatha KT, Bhatathiri VN, Bose T. Effectiveness of triclosan in the management of radiationinduced oral mucositis: a randomized clinical trial. J Cancer Res Ther. 2010;6:466-72.

https://doi.org/10.4103/0973-1482.77109

30. WC T. Magic mouthwash: an update. Pharmacist's Letter/ Prescriber's Letter 2009;25:251103.

31. Sonis S. The quest for effective treatments of mucositis. J support Oncol. 2011;9:170-1.

https://doi.org/10.1016/j.suponc.2011.07.001

32. McGuire DB, Fulton JS, Park J, Brown CG, Correa MEP, Eilers $\mathrm{J}$, et al. Systematic review of basic oral care for the management of oral mucositis in cancer patients. Support Care Cancer. 2013;21:3165-77. https://doi.org/10.1007/s00520-013-1942-0

33. Kuk JS, Parpia S, Sagar SM, Tsakiridis T, Kim D, Hodson DI, et al. A randomized phase III trial of magic mouthwash and sucralfate versus benzydamine hydrochloride for prophylaxis of radiation-induced oral mucositis in head and neck cancer. J Clini Oncol. 2011;29(15_suppl):5521-.

34. Cerchietti LC, Navigante AH, Bonomi MR, Zaderajko MA,
Menendez PR, Pogany CE, et al. Effect of topical morphine for mucositis-associated pain following concomitant chemoradiotherapy for head and neck carcinoma. Cancer. 2002;95:2230-36. https://doi.org/10.1002/cncr.10938

35. Sarvizadeh M, Hemati S, Meidani M, Ashouri M, Roayaei M, Shahsanai A. Morphine mouthwash for the management of oral mucositis in patients with head and neck cancer. Adv Biomedi Res. $2015 ; 4: 44$.

https://doi.org/10.4103/2277-9175.151254

36. Intahphuak S, Khonsung P, Panthong A. Anti-inflammatory, analgesic, and antipyretic activities of virgin coconut oil. Pharmaceuti Biol. 2010;48:151-57. https://doi.org/10.3109/13880200903062614

37. Daddy Suradi Halim, Nurul Asma Abdullah, Mohammad Khursheed Alam, Siti Nuraini Bt Samsee, May TS. Comparison of the Effectiveness between Virgin Coconut Oil (VCO) and Triamcinolone for Treatment of Minor Recurrent Aphthous Stomatitis (RAS). Int Medi J. 2014;21:319-20.

38. Kaliamoorthy S, Pazhani A, Nagarajan M, Meyyappan A, Rayar $\mathrm{S}$, Mathivanan S. Comparing the effect of coconut oil pulling practice with oil pulling using sesame oil in plaque-induced gingivitis: A prospective comparative interventional study. J Natural Sci, Biol Medi. 2018;9:165-8.

https://doi.org/10.4103/jnsbm.JNSBM_146_17

39. Chalke S, Zope S, Suragimath G, Varma S, Abbayya K, Kale V. Effect of coconut oil pulling on plaque-induced gingivitis: A prospective clinical study. Int J Green Pharma. 2017;11:750-55.

40. Peedikayil FC, Sreenivasan P, Narayanan A. Effect of coconut oil in plaque related gingivitis - A preliminary report. Nigerian Medical Journal : Journal of the Nigeria Medical Association. 2015;56:143-7. https://doi.org/10.4103/0300-1652.153406

41. Vysakh A, Ratheesh M, Rajmohanan TP, Pramod C, Premlal S, Girish kumar B, et al. Polyphenolics isolated from virgin coconut oil inhibits adjuvant induced arthritis in rats through antioxidant and antiinflammatory action. Int Immunopharma. 2014;20:124-30. https://doi.org/10.1016/j.intimp.2014.02.026

42. Nevin KG, Rajamohan T. Beneficial effects of virgin coconut oil on lipid parameters and in vitro LDL oxidation. Clini Biochemi. 2004;37:830-5.

https://doi.org/10.1016/j.clinbiochem.2004.04.010

43. Zakaria ZA, Somchit MN, Mat Jais AM, Teh LK, Salleh MZ, Long K. In vivo Antinociceptive and Anti-inflammatory Activities of Dried and Fermented Processed Virgin Coconut Oil. Medi Principles Pract. 2011;20:231-6.

https://doi.org/10.1159/000323756

44. Ibrahim AH, Khan MS, Al-Rawi SS, Ahamed MB, Majid AS, AlSuede FS, et al. Safety assessment of widely used fermented virgin coconut oil (Cocos nucifera) in Malaysia: Chronic toxicity studies and SAR analysis of the active components. Regulat toxicol pharmacolog: 
2016;81:457-67.

https://doi.org/10.1016/j.yrtph.2016.10.004

45. Ibrahim AH, Li H, Al-Rawi SS, Majid ASA, Al-Habib OA, Xia $\mathrm{X}$, et al. Angiogenic and wound healing potency of fermented virgin coconut oil: in vitro and in vivo studies. Ameri J translati Res. 2017;9:4936-44.

46. Rajagukguka H, Syukurb S, Ibrahimc S, Syafrizayantid. Beneficial Effect of Application of Virgin Coconut Oil (VCO) Product from
Padang West Sumatra, Indonesia on Palatoplasty Wound Healing. American Scientific Research J Engi, Technolo, and Sci:2017;34:2316.

47. Agero AL, Verallo-Rowell VM. A randomized double-blind controlled trial comparing extra virgin coconut oil with mineral oil as a moisturizer for mild to moderate xerosis. Dermatitis : contact, atopic, occupational, drug. 2004;15:109-16.

https://doi.org/10.2310/6620.2004.04006 